\section{SOI: $1.1 /$ TAS $\quad$ DOI: $10.15863 /$ TAS \\ International Scientific Journal Theoretical \& Applied Science}

\author{
p-ISSN: 2308-4944 (print) e-ISSN: 2409-0085 (online) \\ Year: 2015 Issue: 04 Volume: 24
}

Published: $30.04 .2015 \quad \underline{\text { http://T-Science.org }}$
Svetlana Valeryevna Fedorova

Candidate of Technical Sciences, associate professor,

Irkutsk National Research Technical University, Russia

$\underline{\text { fsta@istu.irk.ru }}$

SECTION 12. Geology. Anthropology. Archeology.

\title{
PHYSICAL AND CHEMICAL AND ELECTRIC INDICATORS OF THE MICALEX
}

Abstract: Physical and chemical properties of a micalex are defined by quality of initial materials and technology of its production. In an assessment of quality of a micalex as dielectric, specific superficial resistance has crucial importance. The size of superficial resistance is in limits $10^{10}-10^{13}$ of Ohms at normal relative humidity and substantially depends on a condition of a surface, and also structure of a blanket.

Key words: micalex, superficial resistance, physical and chemical properties.

Language: Russian

Citation: Fedorova SV (2015) PHYSICAL AND CHEMICAL AND ELECTRIC INDICATORS OF THE MICALEX. ISJ Theoretical \& Applied Science 04 (24): 145-148.

Soi: http://s-o-i.org/1.1/TAS*04(24)25 Doi: crossef http://dx.doi.org/10.15863/TAS.2015.04.24.25

\section{ФИЗИКО-ХИМИЧЕСКИЕ И ЭЛЕКТРИЧЕСКИЕ ПОКАЗАТЕЛИ МИКАЛЕКСА}

Аннотация: Физико-химические свойства микалекса определяются качеством исходных материалов и технологией его изготовления. В оценке качества микалекса, как диэлектрика, удельное поверхностное сопротивление имеет решающее значение. Величина поверхностного сопротивления находится в пределах $10^{10}$ - $10^{13}$ Ом при нормальной относительной влажности и в значительной степени зависит от состояния поверхности, а также структуры поверхностного слоя.

Ключевые слова: микалекс, поверхностное сопротивление, физико-химические свойства.

Кристаллы слюды являются наиболее уникальными представителями мира кристаллических тел. Для них характерно резко выраженное изменение физических свойств с направлением. Это обусловлено своеобразием кристаллической структуры: большой энергией связи частиц в пакете и значительно меньшей между пакетами по плоскости совершенной спайности. Следствием этой анизотропии сил межатомных связей является способность кристаллов слюды расщепляться на тонкие плоскопараллельные пластинки значительной площади, то есть исключительно выраженная анизотропия механических свойств.

Слоистое распределение частиц в структуре приводит к высокой теплопроводности вдоль слоев. Наличие своеобразных извилистых пустот и каналов в межпакетных зонах кристалла и уплотненных барьеров из атомов между ними создает резко отличительные условия для движения ионов вдоль спайности и перпендикулярно к ней.
Это обусловливает различие электрических свойств слюды в двух основных направлениях на несколько порядков. Таким образом, для физических свойств слюды характерна необычайно большая анизотропия, которая широко используется. При этом необходимо постоянно учитывать, что рядом с высокими значениями тех или иных характеристик в кристалле существуют и низкие: для этого достаточно лишь изменить его ориентацию на $90^{\circ}$. Основу кристаллической структуры слюд составляет плоский двойной кремнекислородный пакет. С наружных сторон пакеты ограничены основаниями кремнекислородных тетраэдров. Два элементарных слоя кремнекислородных тетраэдров расположены таким образом, что их основания находятся снаружи, а вершины обращены внутрь. Атомы кремния Si находятся в центрах тетраэдров, а в их вершинах расположены атомы кислорода 0. Гидроксильные группы $\mathrm{OH}$ связаны с алюминием $\mathrm{AL}$, магнием $\mathrm{Mg}$, или железом $\mathrm{Fe}$; получается прочно 
связанный двойной слой, в котором основания тетраэдров находятся в каждом из наружных слоев, а между средними двойными слоями размещаются атомы калия К.

Обладая сходными элементами структуры, слюды в то же время отличаются способом сочленения их в пакеты, природой и энергией связи между последними, характером заселения тетраэдрических и октаэдрических сеток. При раскалывании кристаллов слюды преимущественно рвутся связи AL-O, Si-O расщеплением более вероятно разрушение слабой связи К-O, а также ослабление связи $\mathrm{AL}-$ O. Поэтому на поверхности слюд обнаруживаются K, $\mathrm{Mg}, \mathrm{O}$ и частично AL и $\mathrm{Si}$. Так как усилия валентных связей К -O равны $1 / 12$, то ионы $\mathrm{K}$ и $\mathrm{Mg}$ с наполовину некомпенсированным зарядом, будут непрочно удерживаться поверхностью слюд, плоскость спайности будет состоять из анионов кремнекислородных тетраэдров. На торцевых участках будут присутствовать ионы алюминия, кислорода и частично кремния.

Межплоскостные связи наиболее слабые, что и проявляется в весьма совершенной спайности, то есть кристаллы легко расщепляются по межпакетным плоскостям. Эти плоскости совпадают с плоскостями элементарной ячейки кристалла. Концентрация атомов в межпакетных слоях примерно в три раза меньше, чем в других направлениях в кристалле, а поэтому силы взаимодействия между пакетами на один порядок меньше величины внутренних сил. Это обстоятельство является основной причиной резкого различия физических свойств слюд в двух направлениях: параллельном и перпендикулярном плоскости спайности. По термическим и химическим свойствам слюда обладает высокими характеристиками, а эти параметры в свою очередь, влияют на свойства микалекса. В электроизоляционной технике применяют, в основном, флогопит $\mathrm{KMg}_{3}\left[\mathrm{Si}_{3} \mathrm{ALO} 10\right] \quad(\mathrm{OH})_{2} \quad$ и $\quad$ мусковит $\mathrm{KAL}_{2}\left[\mathrm{SiAlO}_{10}\right](\mathrm{OH}) 2$. Слюда обладает высокими электрическими характеристиками, низкими диэлектрическими потерями, высокими поверхностным и объемным удельными электросопротивлениями, высокой электрической прочностью. Она обладает большой механической прочностью, негорючестью, химической устойчивостью [1, c.76].

Наиболее полное использование в электроизоляционной промышленности находит мусковит: он выдерживает нагрев до $600^{\circ} \mathrm{C}$. Флогопит является гигроскопичной слюдой: по своей природе он более мягок и труднее расщепляется на тонкие слои по сравнению с мусковитом, но более термостоек и выдерживает нагрев до $800^{\circ} \mathrm{C}[4$, с.111].

Термостойкость кристаллов флогопита на 200-300 выше, чем мусковита [5, с 59]. Это объясняется тем, что и флогопит, и мусковит до температуры $400 \mathrm{C}$ выделяют примерно равное количество газов. При повышении температуры на $100 \mathrm{C}$ наблюдается резкое увеличение газовыделения у мусковита, главным образом, за счет выхода воды. Для флогопита газовыделение практически остается на уровне прогрева при $400{ }^{\circ} \mathrm{C}$ [7, c.97].

Дегидроксилацию флогопита [8, с. 102] связывают с удалением структурной воды. Для него область дегидроксилации составляет от 800 до 1000 С. Учитывая структурные особенности кристаллов слюды, ее слоистость, авторы предполагают, что образовавшаяся вода будет концентрироваться в межслоевом промежутке, обусловливая диффузионное сопротивление удаленной воды из межпакетной зоны. Для образцов Арябиловского флогопита в интервале $700-900^{\circ} \mathrm{C}$ протекает два процесса удаления воды (вода удаляется по двум механизмам). В интервале от 700 до $800^{\circ} \mathrm{C}$ происходит удаление воды в диффузионном режиме. При $800^{\circ} \mathrm{C}$ практически завершается процесс удаления межслоевой воды, а выше $800 \mathrm{C}$ начинается процесс дегидроксилации - удаление химически связанной воды. У флогопитов Каталах и Ковдор процесс дегидроксилации начинается в тот период, когда выделение межслоевой воды еще не завершено, тогда как у образцов Арябиловского флогопита, процесс удаления межслоевой воды четко разграничен. При изучении природного флогопита [9, с. 47] было выяснено, что у него потеря массы воды происходит в три этапа: выход адсорбированной воды - 40-220 $0^{\circ}$ межслоевой воды - 220-900, удаление конституционной воды - $960^{\circ}$ и выше. Слюда, отличающаяся повышенным содержанием фтора, является более термостойкой.

Явление резкого увеличения газовыделения при повышенных температурах у кристаллов мусковита обусловлено дегидратацией некоторой части октаэдров структурного мотива, вследствие чего кристалл растрескивается, создавая благоприятные условия для выхода газов, главным образов, воды. В работе [29, с.123] рассматриваются рентгеновские исследования флогопитов. Они показали, что общим для всех является наличие серии отражений, соответствующих высоте слоя $\mathrm{d}_{001}$, равной примерно 20 А. В эту серию хорошо вписываются обычные для флогопита отражения с $\mathrm{d}_{001}=10 \mathrm{~A}$. Рентгенограмма, содержащая только отражения с названными $\mathrm{d}_{001}$, получена лишь от Ковдорского флогопита. На рентгенограммах всех остальных флогопитов, а именно Алданского и 
Слюдянского месторождений, присутствуют от одной до нескольких серий отражений с различными $\mathrm{d}_{001}$. Выявлено, что количественное отношение фаз - примесей является индивидуальной характеристикой каждого образца. Флогопиты Ковдорские и Слюдянские характеризуются наличием фазы с $\mathrm{d}_{001}$ равным 14 A. Кроме этой фазы присутствуют в незначительных, количествах фазы с $\mathrm{d}_{001}$, равным примерно 11 и 13 А. Соотношение интенсивности самых сильных отражений каждой серии может служить мерой сравнительной оценки содержания фаз в образце. Так наибольшее количество фаз с dooi, равным 14 А, содержится в Ковдорском флогопите. Рентгенограммы Алданских флогопитов более разнообразны. Наряду с целочисленными сериями отражения переслоенных структур с $\mathrm{d}_{001}$. равными 16 А $(9+$ 7) , 24 А $(10+4)$ в основном, присутствуют отражения с $\mathrm{d}_{001}$ равные примерно 7,5 А. Также известны работы по исследованию слюды при ее облучении интенсивным электромагнитным излучением [10, с.12] . Были изучены структурные изменения монокристаллов флогопита Ковдорского месторождения при нагревании в интервале температур от 27 до $977^{\circ} \mathrm{C}$ и воздействие ИК-лазерного излучения на слюду мусковит.

Результаты терморентгенографических исследований флогопитов показали, что до температуры $527^{\circ} \mathrm{C}$ существенных изменений на дифракционной картине не наблюдается, но при более высокой температуре они легко фиксируются. Примечательным является различный характер изменения величины $\mathrm{d}_{001}$ и Boon ${ }^{\mathrm{B}}$ следующих друг за другом циклах нагрев охлаждение. Зависимость $\mathrm{d}_{001}=\mathrm{f}(\mathrm{T})$ является практически линейной и при втором нагреве точно воспроизводит аналогичную зависимость первого нагрева в перекрывающемся интервале температур и продолжает ее ход при более высоких температурах КТР $\mathrm{d}_{001}=16^{*} 10 \mathrm{~K}-{ }^{1}$. При температуре $727^{\circ} \mathrm{C}$ во флогопите образуется новая кристаллическая фаза, сохраняющаяся после охлаждения и последующих циклов нагрев охлаждение во всем температурном интервале и отличающаяся от исходной меньшими значениями $\mathrm{d}_{001}$ и более высоким значением КТР $\mathrm{d}_{001}=18,7-10-^{6} \mathrm{~K}^{-1}$. При температуре $>527^{\circ} \mathrm{C}$ наблюдается рост полуширины отражения исходной фазы, свидетельствующей о процессе расслоения образца, т.е. уменьшения размеров ОКР в направлении, перпендикулярном плоскости спайности. У вновь возникшей фазы эта характеристика имеет наибольшее значение при температуре возникновения фазы, а затем уменьшается до $877^{\circ} \mathrm{C}$. При нагревании, по мере увеличения содержания новой фазы в образце происходит увеличение интенсивности соответствующего отражения, являющегося составной частью отражения исходной фазы. В результате фазового перехода образуется структура, имеющая меньший объем элементарной ячейки по сравнению с исходным кристаллом. Основной вклад в изменение объема вносит параметр "С". Таким образом, у флогопитов установлен высокотемпературный разовый переход. В результате образуется кристаллическая фаза, характеризующаяся меньшими значениями базального параметра и объема элементарной ячейки, устойчивая в широком температурном интервале. Уменьшение параметров является главным отличием фазового перехода во, флогопитах от перестройки структуры мусковита при нагревании. У мусковитов, в результате процесса дегидроксилации, образуется фаза, имеющая большие, по сравнению с исходной структурой, значения "C" и "V". Для оценки характера изменений, происходящих в структуре мусковита под действием ИК-лазерного излучения, были проведены параллельные исследования образцов, подвергнутых прогреву при фиксированных температурах и воздействию ИК-лазерного излучения различной мощности.

Авторами была исследована область частот, примыкающая к частоте лазерного излучения $\left(943 \mathrm{~cm}^{-1}\right)$. Поглощение на $\mathrm{v}=943 \mathrm{~cm}^{-1}$ может быть обусловлено в слюде длинноволновым крылом полосы, поглощения $\mathrm{Si}-0-\mathrm{Si}\left(\max \mathrm{v}=1000 \mathrm{~cm}^{-1}\right)$, $\mathrm{Si}-0-\mathrm{Al}$ (max v 920-960 $\mathrm{cm}^{-1}$ ) и поглощением деформационных колебаний Al-O-H c (max v = 925 см-1 ). Для оценки вклада каждого из указанных колебаний исследовались спектры пластин и порошков мусковита после прогрева в течение часа при температурах $497 \mathrm{C}, 847^{\circ} \mathrm{C}$, $997^{\mathrm{C}} \mathrm{C}$ на воздухе и в аргоне.

При прогреве до $497^{\circ} \mathrm{C}$ спектры не изменяются. Это объясняется тем, что при данной температуре изменений в слюде не происходит. По свидетельству авторов, после прогрева до $847^{\circ} \mathrm{C}$ уменьшается интенсивность валентных

колебаний гидроксильных групп (область $3620,3640)$ см, плечо в области $943 \mathrm{~cm}^{-1}$ становится менее выраженным. В температурном интервале от 847 до $997^{\circ} \mathrm{C}$ поглощение в области валентных колебаний 0 - Н полностью исчезает. Таким образом, на основании полученных результатов можно утверждать, что под действием лазерного излучения в слюде происходит резонансное возбуждение преимущественно деформационных колебаний Al-O-H , а также в малой степени колебаний связи Si-O- Al, Si-0-( $\left.\mathrm{Me}^{+}\right)$.

Лазерное облучение мусковита при малых мощностях $\mathrm{P}=2-3,5$ Вт и времени облучения порядка нескольких минут не вносит никаких 
изменений в слюду. А при более высокой мощности - $\mathrm{P}=3,5-6$ Вт возникают изменения, зависящие от длительности излучения. Происходит уменьшение прозрачности слюды, выявление вспучивания и трещин. Структурные изменения авторы изучали с помощью рентгеноструктурного анализа. Им удалось установить, что при малых временах облучения (1-5) с в мусковите, наряду с основной фазой, появляется новая фаза с несколько большими межплоскостными расстояниями. С увеличением времени облучения наблюдается уменьшение высоты максимума межслоевого катиона и увеличение полуширины максимума. Механизмы структурных превращений мусковита при лазерном облучении и термическом воздействии совпадают с процессами, происходящими в слюде при обычном нагревании. На начальных этапах облучения происходит выход гидроксилов из октаэдрической сетки, что приводит к развороту тетраэдров и гофрировке сетки их внешних оснований. В кристалле образуются трещины, и он мутнеет. При дальнейшем облучении происходит вынос межслоевого катиона, и появляются области с сильно искаженной внутренней сеткой, гофрировка оснований тетраэдров возрастает так, что параметр "C" растет. В течение некоторого времени эта разрушенная фаза соседствует с деформированной исходной. Затем концентрация последней уменьшается, структура кристалла теряет устойчивость, и он разрушается.

\section{References:}

1. Volkov KI, Zagibalov PN, Mecik AI (1971) Svojstvo, dobycha i pererabotka sljudy,I.:Vost-Sib.kn. izd-vo. 1971. - pp.340.

2. (1971) Iskusstvennaja sljuda. Bibliograficheskij ukazatel' otechestvennoj i inostrannoj knizhnoj, zhurnal'noj i patentnoj literatury za 1962-1966 gg. -M.JuNTI VIJeMS, 1971. $-157 \mathrm{p}$.

3. (1965) A. s. 175486 SSSR, NKI 12 S 2 Sposob poluchenija kristallov $\sin \neg$ teticheskoj sljudy / I.N.Anikin E.E. Kochetkova, SSSR.- № 374904/26-25. -Zajavleno 6.01.64; Opubl.9.10.65.- Bjul.- №20.

4. Lejzerzon MS, Feofilova OP (1960) Novomikaleksy i mikoplastik. Voprosy radiojelektroniki: Ser. IV, 1960. -Vyp. 5, - pp. 28-43.

5. Anikin IN, Kishko VA, Matveev SI (1967) Isskustvennaja sljuda. Tehn. inf. CNIITJe Stroit. Ser. Promyshlennoe proizvodstvo nerudnyh i nemetallorud. materialov. - L., 1967. -Vyp. 3. - pp. 21-23.

6. Kolganova VA, Asnovich JZ, Zabyrina KI (1974) Jelektroizoljacionnye materialy na osnove sljudy ftorflogopit. Jelektrotehnicheskaja promyshlennost'. Ser. Jelektrotehnicheskie materialy. - I.,1974. - Vyp 2. 52. -pp.3-5.
7. Veksler AS, Ozhigov VN, Mecik MS (1983) Issledovanie termostojkosti kristallov sljudy. Issledovanija $\mathrm{v}$ oblasti fiziki tverdogo tela.I.:Vost-Sib.kn. izd-vo, 1983.-Vyp.1. -pp. 164168.

8. Mecik MS (1988) Termicheskie svojstva kristallov sljudy.-I.:Izd-vo Irk.un-ty, 1988. -pp. 184.

9. Tjurin NG, Shishelova TI, Leonova NV, Obuhova AG (1985) Kojefficient diffuzii vody pri degidroksilacii flogopita. VINITI. -Irkutsk, 1985. -pp.2-7.

10. Shishelova TI, Leonova NV, Novgorodceva TI (1990) Ispol'zovanie prirodnogo ftorflogopita dlja izgotovlenija nagrevostojkih bumag. Izv. VUZov. Neorganicheskie materialy, 1990, №5,- pp.1117-1119.

11. Kuznecova GA, Krinari GA, Liopo VA (1989) Osobennosti kristal $\neg$ licheskogo fazovogo sostava prirodnyh flogopitov. VINITI.-Irkutsk, 1989. -pp. 30.

12. Liopo VA, Mecik MS, Kuznecova GA, Vojna VV, Kovalevskaja TI, Kalihman VM (1990) Strukturnye izmenenija $\mathrm{v}$ kristallah sljud pri lazernom obluchenii. Izvestija vuzov. Fizika. Tomsk, 1990.- pp.21.

13. Lejzerzon MS (1962) Sinteticheskaja sljuda.M-L. Gosjenergoizdat, 1962. -pp. 160-174. 